\title{
Pediatric superior semicircular canal dehiscence: illustrative case and systematic review
}

\author{
Carlito Lagman, MD, ${ }^{1}$ Vera Ong, ${ }^{1}$ Lawrance K. Chung, BS, ${ }^{1}$ Lekaa Elhajjmoussa, BS, ${ }^{1}$ \\ Christina Fong, MD, ${ }^{2}$ Anthony C. Wang, MD, ${ }^{1}$ Quinton Gopen, MD, ${ }^{3}$ and Isaac Yang, MD ${ }^{1,3,4}$ \\ Departments of ${ }^{1}$ Neurosurgery, ${ }^{2}$ Pediatrics, ${ }^{3}$ Radiation Oncology, and ${ }^{4}$ Head and Neck Surgery, David Geffen School of \\ Medicine, University of California, Los Angeles, California
}

\begin{abstract}
OBJECTIVE The purpose of this study is to present an illustrative case of pediatric superior semicircular canal dehiscence (SSCD) and to systematically review the current published literature in the pediatric population.

METHODS An electronic search of the Scopus, Web of Science, PsycINFO, Cochrane, and Embase databases was performed by 2 independent authors through January 2017. Search term combinations included "pediatrics," "children," "canal," and "dehiscence." Inclusion criteria were as follows: English, full-text clinical studies, case reports, and case series describing pediatric patient(s) (younger than 18 years) with CT evidence of SSCD. Baseline patient demographic characteristics, clinical presentations, dehiscence characteristics, management strategies, and outcome data were extracted.
\end{abstract}

RESULTS A total of 14 studies involving 122 patients were included in the quantitative synthesis. The patients' mean age was 7.22 years. Male predominance was observed (approximate male-to-female ratio of 1.65:1). Neurodevelopmental disorders were common $(n=14,11.5 \%)$. Auditory signs and symptoms were more common than vestibular signs and symptoms. Hearing loss $(n=62,50.8 \%$ ) was the most common auditory symptom and an indicator for imaging evaluation. Vertigo was the most common vestibular symptom $(n=8,6.6 \%)$. Hearing aids were recommended in 8 cases $(6.6 \%)$, and surgical repair was performed in 1 case $(0.8 \%)$. Symptom outcomes and follow-up durations were infrequently reported.

CONCLUSIONS The authors' data suggest that in pediatric SSCD, males are more commonly affected than females. This is different than the adult population in which females are predominantly affected. A history of otologic and/or neurodevelopmental abnormalities was common. There was a preponderance of auditory symptoms in this age group. Conservative management was favored in the majority.

https://thejns.org/doi/abs/10.3171/2017.3.PEDS1734

KEY WORDS dehiscence; pediatrics; superior semicircular canal

$\mathrm{S}$ UPERIOR semicircular canal dehiscence (SSCD) is a defect of the skull base that is gaining increasing recognition among neurosurgeons. ${ }^{1,2,5}$ It is described as a pathological aperture commonly at the level of the arcuate eminence of the petrous temporal bone. ${ }^{2}$ The exact epidemiology of SSCD is not elucidated, but the highest incidence is in children younger than 2 years of age, and this suggests a congenital precedent. ${ }^{2,29,31}$ Prior imaging studies have reported SSCD incidence as high as $10 \%$ in children. ${ }^{2,4,29}$
SSCD syndrome is characterized by auditory and vestibular disturbances. The pathologic cascade leading to development of the syndrome is not entirely understood. It is thought that endolymphatic ebb and flow through the superior semicircular canal is inadvertently shunted through the osseous defect into the cranial vault. ${ }^{2}$ Intracanalicular and intracranial pressure differentials become dependent on one another at the dehiscence and produce abnormal stimulation of kinocilia and stereocilia during angular acceleration.

ABBREVIATIONS ASD = autism spectrum disorder; $\mathrm{CP}=$ cerebral palsy; $\mathrm{GH}$ = growth hormone; HRCT = high-resolution computed tomography; IGF = insulin-like growth factor; SSCD = superior semicircular canal dehiscence.

SUBMITTED January 23, 2017. ACCEPTED March 31, 2017.

INCLUDE WHEN CITING Published online May 26, 2017; DOI: 10.3171/2017.3.PEDS1734. 


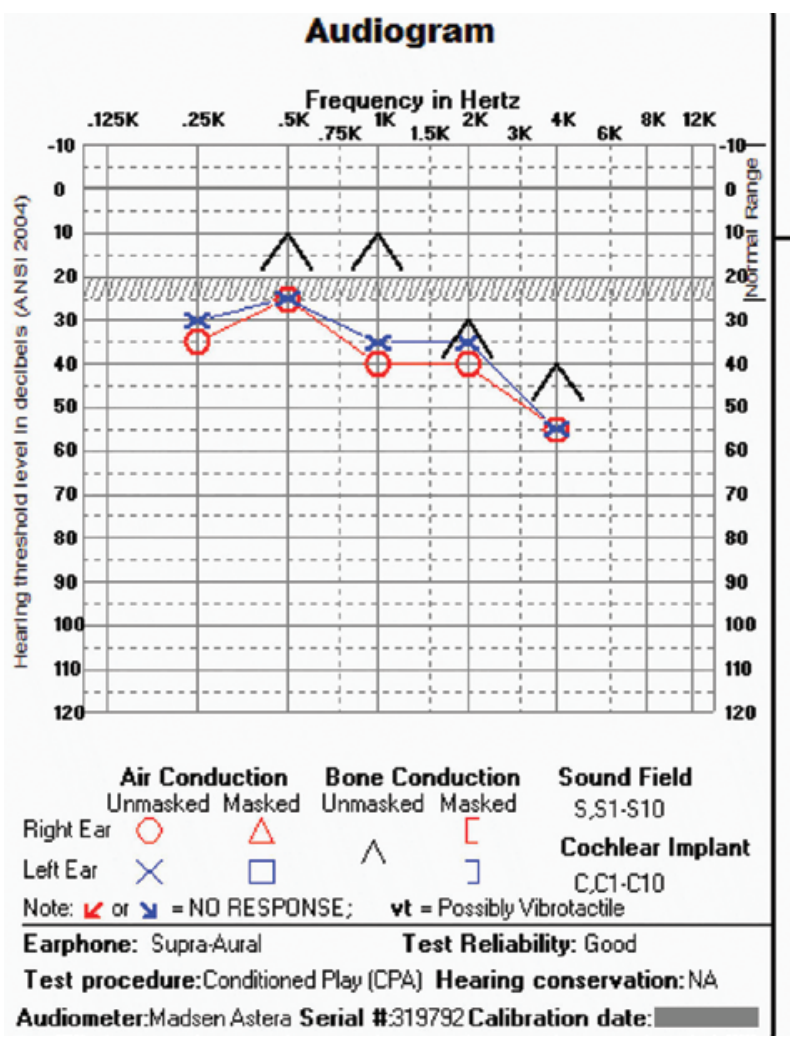

\begin{tabular}{|c|c|}
\hline \multicolumn{2}{|c|}{ Speech Audiometry } \\
\hline \multirow{2}{*}{$\begin{array}{l}\text { Speech Reception } \\
\text { Threshold: }\end{array}$} & Signal source: $\underline{M L V}$ \\
\hline & Right Threshold $\underline{20}$ \\
\hline \multirow{3}{*}{$\begin{array}{l}\text { Phoneme \& Worc } \\
\text { Recognition: }\end{array}$} & Signal source: $\mathrm{MLV}$ \\
\hline & $-\ldots \% @$ \\
\hline & $\overline{80} \% @ \overline{40} \mathrm{~dB} S \mathrm{~L}$ \\
\hline
\end{tabular}
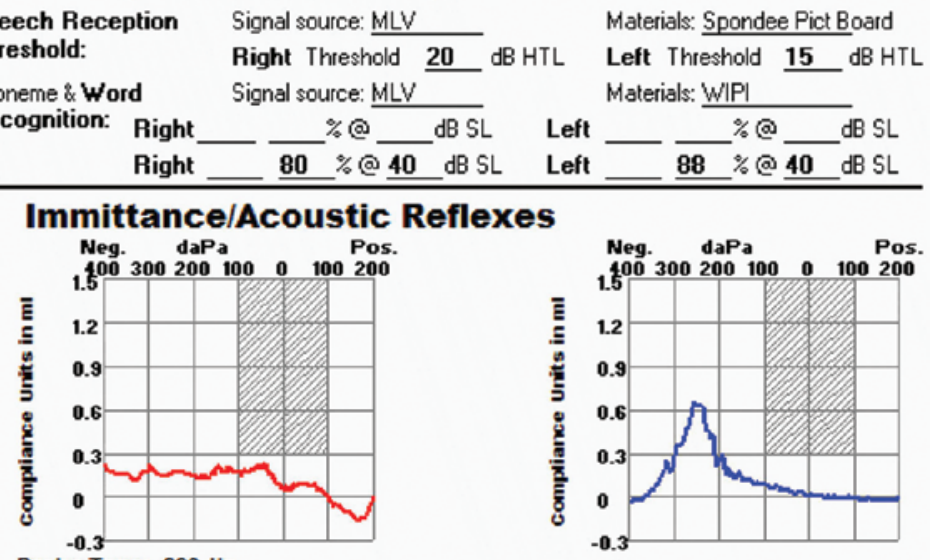

Probe Tone: $226 \mathrm{~Hz}$

Tymp. Type

M.E. Pressure

Right

Volume in $\mathrm{ml}$

Compliance Units

Right -97

Right $\overline{11.75}$

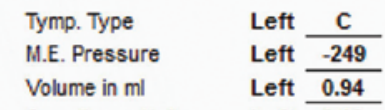

$\$$ Sound Right $|500| 1 \mathrm{~K} \frac{\mathbf{0 . 1 7}}{\mathrm{2}}$

Compliance Units Left $\mathbf{0 . 6 2}$

\begin{tabular}{l|l|l|l} 
Sound Right & 500 & $1 \mathrm{~K}$ & $2 \mathrm{~K}$ \\
\hline Reflex (HL) & & & \\
\hline Decay (sec.) & & & \\
\hline Deflex (HL) & & & \\
\hline Decay (sec.) & & &
\end{tabular}

\begin{tabular}{l|l|l|l|l|} 
Sound Left & 500 & $1 \mathrm{~K}$ & $2 \mathrm{~K}$ \\
\hline Reflex (HL) & & & \\
\hline Decay (sec.) & & & \\
\hline$\overline{\mathbf{D}}$ Reflex (HL) & & & \\
\hline Decay (sec.) & & & \\
\hline
\end{tabular}

SL= Sensation Level $\quad$ IR $=$ No Response Masked opposite ear $=$ * CNT $=$ Could Not Test $\quad$ DNT $=$ Did Not Test $\quad$ ARTF $=$ Artifact

FIG. 1. Audiogram from the patient in the illustrative case. ANSI = American National Standards Institute; CONTRA = contralateral; $\mathrm{HL}=$ hearing level; $\mathrm{HTL}=$ hearing threshold level; IPSI = ipsilateral; M.E. = middle ear; MLV = monitored live voice; Neg. = negative; Pict = Picture; Pos. = positive; sec. = seconds; SL = sensation level; Tymp. = tympanogram; WIPI = Word Intelligibility by Picture Identification. Figure is available in color online only.

Auditory symptoms include autophony, tinnitus, hearing loss, aural fullness, and hyperacusis., ${ }^{2,5}$ Vestibular symptoms include disequilibrium, dizziness, and vertigo. ${ }^{2,5}$ Sound-induced dizziness (Tullio phenomenon) and pressure-induced nystagmus (Hennenbert sign) are characteristic findings. ${ }^{2}$ These signs are not pathognomonic but are highly suggestive of SSCD. Other symptoms include oscillopsia and headache. Individual symptoms are sufficient to impact quality of life, and when combined, symptoms can be severely debilitating.

Management paradigms include nonoperative and operative measures; the former includes trigger avoidance, tinnitus retraining therapy, medical management, and frequent follow-up visits with serial imaging. Patients with severely debilitating symptoms who have not experienced adequate relief with conservative measures are considered surgical candidates. ${ }^{2,5}$ Evidence in support of conservative management of SSCD in children has been gleaned from a multitude of single-institution, retrospective studies. To date, the literature regarding pediatric SSCD has yet to be effectively amassed and systematically surveyed. In light of this, the authors sought to provide a comprehensive quantitative review and improve clinical characterization of pediatric SSCD.

\section{Illustrative Case}

A 5-year-old boy with a history of recurrent otitis me- dia (which had been treated with Pope tympanostomy tube placement), speech and language delay, and mild-tosevere bilateral sensorineural hearing loss-worse on the right (Fig. 1)-was evaluated by our team for progressive hyperacusis. His ear examination was unremarkable. In November 2014, at 3 years and 9 months of age, the patient had a temporal bone CT (unavailable) at an outside hospital to determine the cause of his hearing loss, which demonstrated right SSCD and severe thinning above the left superior semicircular canal. The patient had no other additional tests. The possibility that the SSCD could be the cause of the low- and midfrequency conductive hearing loss was discussed with the family. However, it did not entirely explain the higher-frequency sensorineural hearing loss. The patient presented to our clinic with more frequent and more severe reactions to ambient noise and loud sounds. For example, the parents described one instance in which the smoke detectors went off, and he fell immediately to the floor in a fetal position with his hands over his ears, crying hysterically (Fig. 2). Currently, this patient's condition is being managed conservatively with hearing aids and frequent follow-up visits.

\section{Methods}

\section{Protocol and Registration}

This systematic review was prepared according to the Preferred Reporting Items for Systematic Review and Me- 


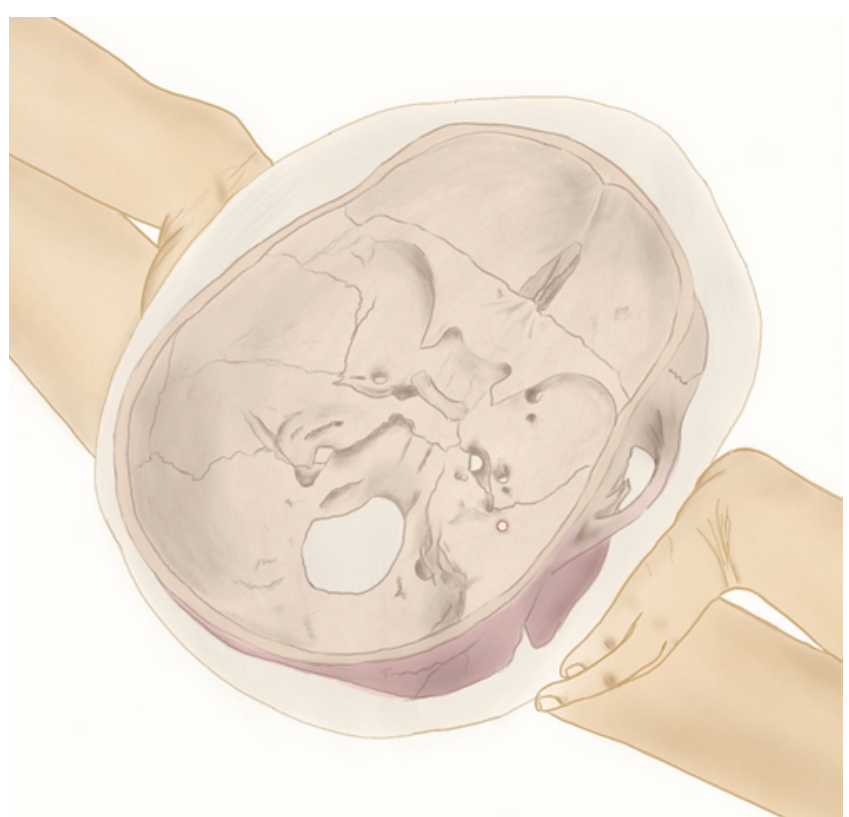

FIG. 2. Artist's interpretation of right-sided pediatric SSCD (denoted by small red circle). Artist Lekaa Elhajjmoussa. Copyright Isaac Yang. Published with permission. Figure is available in color online only.

ta-Analyses Protocols (PRISMA-P) and is registered in the PROSPERO international prospective register of the National Institute for Health Research (CRD42017058160). Institutional review board approval was not required for this study. Consent for publication of details of the illustrative case was obtained from the patient's parents.

\section{Data Sources}

Scopus, Web of Science, PsycINFO, Cochrane, and Embase databases were independently searched by the first (C.L.) and second (V.O.) authors through January 2017, using a strategic combination of search terms: "pediatrics," "children," "canal," and "dehiscence." Items were filtered by language (English), text availability (full text), and article type (clinical studies and trials, case reports, and reviews). Duplicates were discarded. Titles and abstracts were screened, and relevant full-text articles were selected. Bibliographies were also reviewed for additional studies.

\section{Study Selection}

English, full-text clinical studies, case reports, and case series describing pediatric patient(s) (younger than 18 years of age) with high-resolution computed tomography (HRCT) evidence of SSCD were included. Studies describing adult patients (18 years of age or older) and those reporting dehiscences of the posterior and/or lateral semicircular canals, or thinning of the tegmen tympani were excluded. The illustrative case presented above was excluded from quantitative synthesis.

\section{Data Extraction}

Patient demographic characteristics included mean age, sex, medical history, and clinical presentation. Medical history was categorized as neurodevelopmental (autism spectrum disorder [ASD], cerebral palsy [CP], and Down syndrome), ear anomalies (deformed auricles, microatresia, ossicular abnormalities, malformed malleus, malformed incus, displaced incus and stapes, and enlarged vestibular aqueduct), cholesteatoma, ear infection, and others (Ménière's disease, obstructive sleep apnea, Chiari I malformation, and tracheomalacia).

Symptoms were categorized as auditory or vestibular. Auditory symptoms included hearing loss (conductive, sensorineural, and mixed), hyperacusis, tinnitus, autophony, and aural fullness. Vestibular symptoms included vertigo, disequilibrium, and dizziness. Dehiscence laterality and management were recorded. Management was classified as conservative (observation, tinnitus retraining therapy, medical management, and/or frequent follow-ups), hearing aid, and/or surgery. The primary outcome was symptom stability or improvement.

\section{Data Synthesis}

Descriptive statistics for the aforementioned variables were ascertained using SAS version 9.3 (SAS Institute Inc.). Means (and mean of means for age), standard deviations, ranges, frequencies, and relative percentages are reported appropriately. Percentages were calculated based on the entire cohort of unique patients. Assessment of risk of bias was not performed because the study is purely descriptive.

\section{Results}

\section{Search Results}

A total of 231 items were retrieved from 3 electronic databases (Scopus, Web of Science, and PubMed). Results of PsycINFO, Cochrane, and Embase searches were nullified after removal of duplicates. A total of 40 full-text articles were reviewed; 14 retrospective studies, involving 122 unique patients, satisfied the inclusion criteria.

\section{Patient Demographics}

The mean (of means) patient age was 7.22 years (SD 5.18, range 0.79-17 years). Male predominance was observed $(n=56,45.9 \%)$ with an approximate male-to-female ratio of 1.65:1. Neurodevelopmental disorders were the most common component of past medical histories among those reported $(\mathrm{n}=14,11.5 \%$ [ASD, $\mathrm{n}=9 ; \mathrm{CP}, \mathrm{n}$ $=4$; Down syndrome, $\mathrm{n}=1]$ ), followed by ear anomalies $(\mathrm{n}=13,10.7 \%)$, cholesteatoma $(\mathrm{n}=3,2.5 \%)$, and ear infections $(n=2,1.6 \%)$. Other abnormalities $(n=8,6.6 \%)$ were also reported and included craniofacial abnormalities ( $\mathrm{n}=4,3.3 \%)$, Chiari I malformation $(\mathrm{n}=2,1.6 \%)$, Ménière's disease $(\mathrm{n}=1,0.8 \%)$, and obstructive sleep apnea $(n=1,0.8 \%)$. General otologic history $(n=15,12.3 \%)$ was more common than neurodevelopmental disorders $(n=14$, $11.5 \%$ ) after combining ear anomalies, cholesteatoma, ear infections, enlarged vestibular aqueduct, and Ménière's disease.

\section{Clinical Presentation}

Hearing loss $(n=62,50.8 \%)$ was the most common 
auditory symptom, followed by hyperacusis ( $\mathrm{n}=9,7.4 \%)$, tinnitus $(\mathrm{n}=4,3.3 \%)$, autophony $(\mathrm{n}=3,2.5 \%)$, and aural fullness $(n=2,1.6 \%)$. Vertigo $(n=8,6.6 \%)$ was the most common vestibular symptom, followed by disequilibrium $(\mathrm{n}=7,5.7 \%)$, and dizziness $(\mathrm{n}=2,1.6 \%)$. Auditory signs and symptoms dominated the clinical pictures with an auditory-to-vestibular signs and symptoms ratio of 4:1. A total of 12 studies reported that hearing loss was the most common indication for HRCT. The right superior semicircular canal was most commonly affected $(\mathrm{n}=47,38.5 \%)$ followed by the left $(n=38,31.2 \%)$. Bilateral SSCD was least common $(n=25,20.5 \%)$.

\section{Management and Outcomes}

Management and outcomes were rarely provided in the studies reviewed $(\mathrm{n}=6,4.9 \%$ and $\mathrm{n}=2,1.6 \%$, respectively). Hearing aid use was common among the patients included ( $\mathrm{n}=8,6.6 \%)$. Of these 8 patients, 1 individual had used a hearing aid before undergoing repair of SSCD via a middle fossa craniotomy. Symptom outcomes were reported in 2 studies: $80 \%$ of patients on average remained stable or experienced improvement. Follow-up was not reported.

\section{Discussion}

In 1998, Minor et al. published a case series of 8 patients who presented with sound- and pressure-induced vertigo, oscillopsia, and/or disequilibrium. ${ }^{21}$ In those patients, CT scans demonstrated dehiscences of the bones overlying the superior semicircular canals. Since then, several cases and clinical studies have attempted to further elucidate this rare defect. The precise etiology of SSCD is unknown, but malposition of primitive otocysts and migratory disturbances of mesenchymal cells during formation of the apical cap of the superior semicircular canals have been demonstrated through computer simulation. ${ }^{2,33}$ The literature surveyed provided support for both congenital and acquired etiologies.,2,22

In a recent study, $\mathrm{Bi}$ et al. provided an extensive review involving the adult instances of this disorder and discussed potential "pitfalls" in the management of patients with this unusual pathological entity. ${ }^{2}$ The authors provided an eloquent review on SSCD and alluded to the deficiencies in the pediatric literature. To address these deficiencies, we provide a quantitative summary of published cases of pediatric SSCD and highlight the divergent features of the clinical presentation and management. A total of 14 articles $4,10,11,14,15,18,20,22,23,29,31,32,34-36$ comprising 122 cases were reviewed.

\section{Demographics}

The mean (of means) age was 7.22 years, which is consistent with a previous study that described pediatric semicircular canal dehiscence. ${ }^{4}$ The majority of patients in the studies reviewed were between the ages of 4 and 12 years, with only 2 studies reporting a mean age younger than 2 years. This latter finding is dissimilar to a study by Sugihara et al., which reported the incidence of SSCD to be highest in patients younger than 2 years of age ${ }^{31}$ False positives (thinning of the tegmen tympani) may have led to overestimation of SSCD in patients younger than 2 years. Publication biases are also apparent given the number of studies that reported associations with neurodevelopmental disorders and ear anomalies. It is possible that evaluation of those primary comorbidities, combined with unfamiliarity with the syndrome, delayed diagnoses of SSCD (Tables 1 and 2).

Our patient is a boy, and this is in accordance with the observed male predominance (approximate male-tofemale ratio of 1.65:1). Crovetto et al. performed a systematic review of adult SSCD and reported an inverse and less robust ratio (female-to-male ratio of 1.23:1) ${ }^{6}$ The reason for the observed sexual dimorphism is poorly understood but probably related to temporal variances in growth and sex hormones between males and females. Skeletal maturation is dependent on thyroid hormones, growth hormone (GH), and insulin-like growth factor 1 (IGF-1). ${ }^{19}$ At prepubertal stages, secretion of $\mathrm{GH}$ in males parallels that in females. However, growth velocity is slower in males (6.4 $\mathrm{cm} /$ year) than in females $(7.1 \mathrm{~cm} /$ year) during these stages (until approximately 4 years of age). ${ }^{27}$ The pubertal peak is marked by a significant increase in serum concentration of IGF-1, which corresponds to a spike in the rate of bone growth and height increase, especially in males. ${ }^{26}$

The complex endocrinological interplay may explain the increased incidence of dehiscence in male children.

TABLE 1. Baseline characteristics, signs and symptoms, and management

\begin{tabular}{|c|c|}
\hline Characteristic & No. of Pts (\%) \\
\hline Patients & 122 \\
\hline Male & $56(45.9)$ \\
\hline Female & $34(27.9)$ \\
\hline Not reported & $32(26.2)$ \\
\hline Mean age in yrs (SD) & $7.22(5.18)$ \\
\hline \multicolumn{2}{|l|}{ SSCD } \\
\hline Right & $47(38.5)$ \\
\hline Left & $38(31.2)$ \\
\hline Bilateral & $25(20.5)$ \\
\hline Not reported & $12(9.8)$ \\
\hline \multicolumn{2}{|l|}{$\mathrm{PMH}$} \\
\hline Otologic & $15(12.3)$ \\
\hline Neurodevelopmental & $14(11.5)$ \\
\hline Not reported & 93 (76.2) \\
\hline \multicolumn{2}{|l|}{ SSx } \\
\hline Auditory & $80(65.6)$ \\
\hline Vestibular & $20(16.4)$ \\
\hline Not reported & $22(18)$ \\
\hline \multicolumn{2}{|l|}{ Management } \\
\hline Hearing aids & $8(6.6)$ \\
\hline Conservative & $5(4.1)$ \\
\hline Surgery & $1(0.8)$ \\
\hline Not reported & $108(88.5)$ \\
\hline
\end{tabular}

$\mathrm{PMH}=$ past medical history; Pts = patients; $\mathrm{SSCD}=$ superior semicircular canal dehiscence; $\mathrm{SSX}=$ signs and symptoms. 
TABLE 2. Summary of pediatric SSCD studies

\begin{tabular}{|c|c|c|c|c|c|c|c|}
\hline Authors \& Year & $\begin{array}{l}\text { No. of } \\
\text { Cases }\end{array}$ & $\begin{array}{c}\text { Mean } \\
\text { Age (yrs) }\end{array}$ & $\begin{array}{l}\text { Sex } \\
\text { (n) }\end{array}$ & $\begin{array}{l}\text { Laterality } \\
\qquad(\mathrm{n})\end{array}$ & $\begin{array}{l}\text { PMH } \\
\text { (n) }\end{array}$ & $\begin{array}{l}\text { Auditory SSx } \\
\text { (n) }\end{array}$ & $\begin{array}{l}\text { Vestibular SSx } \\
\text { (n) }\end{array}$ \\
\hline Zhou et al., 2007 & 1 & 12 & $\mathrm{~F}(1)$ & Rt (1) & $\mathrm{EA}(1), \mathrm{CP}(1), \mathrm{CF}(1)$ & $\mathrm{HL}(1)^{*}$ & IM (1), Dz (1), VT (1) \\
\hline Chen et al., 2009 & 14 & - & - & Lt (6), rt (6), bilat (2) & - & $\mathrm{HL}(14)^{*}$ & - \\
\hline Yunker et al., 2009 & 1 & 17 & $M(1)$ & $\mathrm{Lt}(1)$ & $\mathrm{DS}(1)$ & $\mathrm{HL}(1)^{*}$ & - \\
\hline Kanaan et al., 2011 & 1 & 11 & $\mathrm{~F}(1)$ & Bilat (1) & - & $\mathrm{HL}(1)^{*}$ & - \\
\hline Lee et al., 2011 & 7 & 6.86 & $M(1), F(6)$ & Lt (1), rt (2), bilat (4) & $\begin{array}{l}\text { EA (4), CP (1), Chiari } \\
\quad(1), C F(1)\end{array}$ & $\begin{array}{l}\operatorname{AF}(1), H L(6)^{*}, \text { AT } \\
\text { (3), TN (2) }\end{array}$ & $\begin{array}{l}\mathrm{Dz}(3), \mathrm{IM}(5), \mathrm{VT} \\
\quad(5)\end{array}$ \\
\hline Hagiwara et al., 2012 & 6 & 0.79 & - & Lt (3), bilat (3) & - & - & - \\
\hline Haffey et al., 2013 & 3 & - & - & - & $\mathrm{EA}(2)$ & $\mathrm{HL}(3)^{*}$ & - \\
\hline Thabet et al., 2014 & 9 & - & - & - & ASD (9) & $\mathrm{HC}(9)^{*}$ & - \\
\hline Jackson et al., 2015 & 20 & 5.97 & $\mathrm{M}(15), \mathrm{F}(5)$ & Lt (6), rt (11), bilat (3) & $\begin{array}{l}\mathrm{EA}(2), \mathrm{El}(2), \mathrm{MD}(1) \\
\quad \mathrm{CL}(1), \mathrm{CP}(1), \mathrm{CF}(1)\end{array}$ & $\mathrm{HL}(13)^{*}$ & VT (1) \\
\hline Meiklejohn et al., 2015 & 13 & 0.88 & $\mathrm{M}(6), \mathrm{F}(7)$ & Lt (6), rt (6), bilat (1) & - & $\mathrm{HL}(10)^{*}$ & - \\
\hline Saxby et al., 2015 & 11 & 6.81 & $\mathrm{M}(8), \mathrm{F}(3)$ & Lt (6), rt (5) & $\mathrm{CL}(2)$ & $\operatorname{AF}(1), \operatorname{TN}(2), \mathrm{HL}(9)^{*}$ & $\mathrm{IM}(1)$ \\
\hline Wenzel et al., 2015 & 1 & 11 & $F(1)$ & $\mathrm{Rt}(1)$ & OSA (1) & - & $\mathrm{Dz}(1), \mathrm{VT}(1)$ \\
\hline Noonan et al., 2016 & 4 & 1.19 & $\mathrm{M}(2), \mathrm{F}(2)$ & Lt (1), rt (1), bilat (2) & - & $\mathrm{HL}(4)^{*}$ & - \\
\hline Sugihara et al., 2016 & 31 & 5.9 & M (23), F (8) & Lt (8), rt (14), bilat (9) & - & - & - \\
\hline Present study & 1 & - & $\mathrm{M}(1)$ & $\operatorname{Rt}(1)$ & El (1) & $\mathrm{HL}(1)^{\star}, \mathrm{HC}(1)$ & - \\
\hline
\end{tabular}

$\mathrm{AF}=$ aural fullness; $\mathrm{AT}=$ autophony; $\mathrm{CF}=$ craniofacial abnormalities; $\mathrm{CL}$ = cholesteatoma; $\mathrm{DS}=\mathrm{Down}$ syndrome; $\mathrm{Dz}=$ dizziness; $\mathrm{EA}=$ ear anomaly; EI = ear infection; $\mathrm{HC}=$ hyperacusis; $\mathrm{HL}$ = hearing loss; $\mathrm{IM}=$ imbalance; $\mathrm{MD}=$ Ménière's disease; $\mathrm{OSA}=$ obstructive sleep apnea; $\mathrm{TN}=$ tinnitus; $\mathrm{VT}=$ vertigo; - = data not available.

* Hearing loss was the primary indication for temporal bone CT scan rather than a result of the SSCD.

Moreover, estrogen interacts with GH and IGF-1, serving as an integral regulator of bone metabolism in both males and females. ${ }^{19}$ Estrogen deficiency, particularly during postmenopausal stages, is correlated with bone resorption. ${ }^{19}$ The prevalence of osteopenia and osteoporosis in elderly females may explain the increased incidence of dehiscence in female adults. Crovetto et al. reported a significant correlation between decreased thickness of the bone overlying the superior semicircular canal and advanced age $(1.14 \mathrm{~mm}$ in patients younger than 45 years and 1.02 $\mathrm{mm}$ in patients older than 45 years).

We observed a right-sided predilection for SSCD, which is opposite to that observed in adults. ${ }^{6}$ The clinical significance of lateral predilections in SSCD is currently undetermined, but an association with contralateral thinning or dehiscence has been described in cadaveric and radiological studies. , $, 3,30,36$ Our patient had right-sided SSCD with severe thinning over the left superior semicircular canal. Karimnejad et al. proposed a developmental hypothesis that differences in sizes of the parietal and temporal lobes could raise intracranial pressures and continuously erode bone. ${ }^{17}$ In support of this theory is the finding by Pujol et al. that parietal and temporal lobes were significantly larger on the left side as compared to the right. ${ }^{25}$ Geschwind and Galaburda investigated the role of testosterone in the growth of cerebral hemispheres and suggested that higher levels of testosterone in males may contribute to the size of the right cerebral hemisphere. ${ }^{9}$

Although intriguing, these theories do not entirely explain lateral predilections. The brain is not in direct contact with the floor of the middle fossa, and intracranial pressures are dispersed evenly through the cerebrospinal fluid at steady state. Thus, constant focal and unilateral
CSF pulsations at the floor of the middle fossa seem unlikely despite differences in sizes of the lobes. It is possible that transient increases in intracranial pressure during collisions can facilitate erosion of bone. This frames a 2-hit hypothesis, which suggests that a vulnerability plus a secondary event may lead to dehiscence. ${ }^{2}$ Still, no definitive predisposing factors have been described.

\section{Medical History}

General otologic and neurodevelopmental histories are of particular interest in pediatric SSCD and were reported in some patients. Ear anomalies were common and comprised an array of defects including auricle and ossicular abnormalities. Cholesteatomas were also seen in few patients. The presence of associated ear anomalies in the setting of SSCD provides further support for a congenital origin. The genetic underpinnings of SSCD have been the subject of recent investigations but no genetic linkage has yet been affirmatively established. $7,13,23,28$

ASD and CP were the most common neurodevelopmental disorders described. A single patient with Down syndrome and SSCD was identified. Clinicians evaluating children who have ASD, CP, or Down syndrome and in whom SSCD is suspected should remain cognizant of potential language limitations in these specific patient populations. Medical histories (from guardians) are imperative and should include detailed investigation of otologic etiologies, objective hearing tests, and treatments. Our patient did not have any known neurodevelopmental disorders. However, he did have speech and language delay related to his hearing loss.

Studies have shown that postpubescent children with 
ASD, CP, and Down syndrome have lower bone mineral densities at the level of the lumbar spine, femoral neck, and hip, compared to children without those syndromes..$^{8,12,16}$ Such findings have not been reported at the skull base. The bones of the skull base form through endochondral ossification similar to long bones and dissimilar to the remaining bones of the cranial vault. Given that fact, approximately equal reductions in bone mineral density at the skull base would likely be observed if evaluated in patients with neurodevelopmental disorders.

\section{Presentation}

Auditory symptoms were characteristic of pediatric SSCD; hearing loss was frequently reported. Vertigo was the most common vestibular symptom reported. Accordingly, this represents an auditory-to-vestibular symptom ratio of 4:1. In children with SSCD, auditory symptoms often precede vestibular signs, which explains the robust ratio observed. ${ }^{2}$ Perhaps, a more salient feature of pediatric SSCD is that children do not report symptoms the way adults do. That is, children may not perceive auditory and vestibular disturbances as abnormal; internal amplification of sounds may not be interpreted as unusual but rather may be interpreted as a normal phenomenon that necessitates physiological adaptation.

\section{Management}

Nevertheless, hearing loss was the most common indication for CT scans in our analysis, as in previous studies. ${ }^{11,14}$ Similarly, the child in our illustrative case was diagnosed with SSCD during routine investigation of hearing loss. Some studies specifically evaluated temporal bone CT scans to determine the radiological prevalence of SSCD in pediatric patients but did not report the indication for imaging. ${ }^{11,20,31}$ Pfammatter et al. reported that adult patients with dehiscences measuring $2.5 \mathrm{~mm}$ or more on HRCT often presented with cochleovestibular signs and symptoms, whereas adult patients with dehiscences smaller than $2.5 \mathrm{~mm}$ presented primarily with either cochlear or vestibular signs and symptoms. ${ }^{24}$ The mean dehiscence size in that study was $3.9 \mathrm{~mm}$ (range 1-7 mm). Extrapolation of those results suggests that pediatric SSCD patients should present with either cochlear or vestibular signs and symptoms.

Nonoperative management and hearing aids were common in this age group. However, hearing aids were often prescribed after identification of SSCD on CT scans, which were ordered to evaluate for hearing loss. One study was exceptional in that the patient had undergone surgical repair of SSCD, and management outcomes were reported. In that study, Lee et al. ${ }^{18}$ described an 11-year-old girl whose hearing loss had previously been managed with hearing aids and ultimately had surgical repair of SSCD via a middle fossa approach. The patient experienced complete resolution of autophony and tinnitus and improvement in vertigo and hearing.

The most common surgical paths to the dehiscent segment are the middle fossa and transmastoid approaches. The advantages and disadvantages of each approach are a subject of great debate. Hearing status, patient choice, physician comfort, and institutional preference are influen- tial factors. At our institution, a multidisciplinary surgical approach is emphasized. The senior authors (Q.G. and I.Y.) use both a middle fossa craniotomy and a minimally invasive keyhole approach for surgical repair of SSCD. Bi et al. provided a concise summary of the surgical techniques employed in the repair of SSCD, including canal plugging, canal roof resurfacing and capping, and round window reinforcement, but the authors also favored conservative measures for children. ${ }^{2}$ Our patient continues to be managed conservatively, and we believe this is reflective of the natural course of pediatric SSCD.

Based on our comprehensive review of the literature and our experience in this age group, we recommend a multidisciplinary approach, which includes obtaining a detailed neurodevelopmental and otologic history and a rigorous assessment of auditory and vestibular signs and symptoms. Evidence-based management guidelines have yet to be described. We have provided our general approach for evaluation of these patients at our institution (Fig. 3). However, it must be emphasized that treatment and decision-making paradigms are multifaceted and far more complicated than can be depicted by a simple flow diagram.

\section{Limitations}

The limitations of this review were the deficiencies and nonuniformity in outcomes reported. Those are a func-

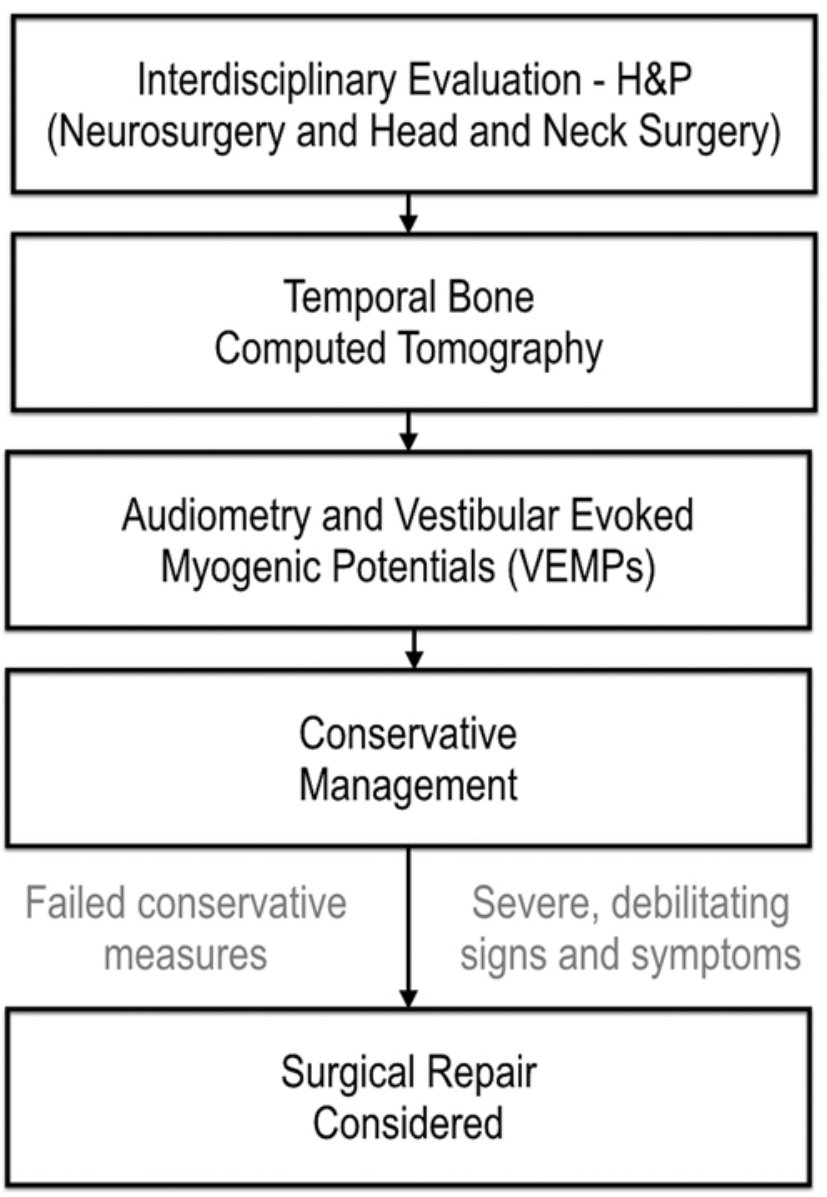

FIG. 3. Evaluation of pediatric SSCD patients at UCLA. H\&P = history \& physical examination. 
tion of nonoperative management, whereby the majority of patients are either lost to follow-up or do not undergo further evaluation. Individual studies are also predisposed to publication and selection biases, and these are well-recognized limitations of retrospective studies and systematic reviews. Moreover, the heterogeneity of studies, small sample sizes, and the inability to extract individual patient data also preclude statistical comparisons.

\section{Conclusions}

SSCD is not well known to many neurosurgeons. Additionally, pediatric neurosurgeons are generally even less familiar with the condition. Our review revealed differences in the pediatric versus the adult SSCD population: 1) male predilection, 2) otologic and neurodevelopmental historical associations, and 3) cochlear symptom predominance. Pediatric SSCD patients often presented with hearing loss and used hearing aids prior to diagnosis. Expectant management is recommended in this age group and includes trigger avoidance, rehabilitation training, medical management, and frequent follow-up visits. Children who do not experience adequate relief with conservative measures or who experience severe, debilitating symptoms may benefit from interdisciplinary surgical evaluation.

\section{Acknowledgments}

Dr. Lagman reports being supported by the Gurtin Skull Base Research Fellowship. Mr. Chung reports being supported by an AMA Foundation Seed Grant and an Alpha Omega Alpha Carolyn L. Kuckein Student Research Fellowship. Dr. Yang reports being partially supported by a Visionary Fund Grant, Eli and Edythe Broad Center of Regenerative Medicine and Stem Cell Research UCLA Scholars in Translational Medicine Program Award, Jason Dessel Memorial Seed Grant, UCLA Honberger Endowment Brain Tumor Research Seed Grant, and Stop Cancer (US) Research Career Development Award.

\section{References}

1. Beckett JS, Lagman C, Chung LK, Bui TT, Lee SJ, Voth BL, et al: Computerized assessment of superior semicircular canal dehiscence size using advanced morphological imaging operators. J Neurol Surg B Skull Base 78:197-200, 2017

2. Bi WL, Brewster R, Poe D, Vernick D, Lee DJ, Corrales CE, et al: Superior semicircular canal dehiscence syndrome. J Neurosurg 13:1-9, 2017

3. Carey JP, Minor LB, Nager GT: Dehiscence or thinning of bone overlying the superior semicircular canal in a temporal bone survey. Arch Otolaryngol Head Neck Surg 126:137147,2000

4. Chen EY, Paladin A, Phillips G, Raske M, Vega L, Peterson $\mathrm{D}$, et al: Semicircular canal dehiscence in the pediatric population. Int J Pediatr Otorhinolaryngol 73:321-327, 2009

5. Chung LK, Ung N, Spasic M, Nagasawa DT, Pelargos PE, Thill K, et al: Clinical outcomes of middle fossa craniotomy for superior semicircular canal dehiscence repair. J Neurosurg 125:1187-1193, 2016

6. Crovetto MA, Whyte J, Rodriguez OM, Lecumberri I, Martinez C, Fernandez C, et al: Influence of aging and menopause in the origin of the superior semicircular canal dehiscence. Otol Neurotol 33:681-684, 2012

7. Crovetto MA, Whyte J, Sarasola E, Rodriguez JA, GarcíaBarcina MJ: Absence of $\mathrm{COCH}$ gene mutations in patients with superior semicircular canal dehiscence. Am J Med Genet A 158A:251-253, 2012
8. Ekhlaspour L, Baskaran C, Campoverde KJ, Sokoloff NC, Neumeyer AM, Misra M: Bone density in adolescents and young adults with autism spectrum disorders. J Autism Dev Disord 46:3387-3391, 2016

9. Geschwind N, Galaburda AM: Cerebral lateralization. Biological mechanisms, associations, and pathology: III. A hypothesis and a program for research. Arch Neurol 42:634654,1985

10. Haffey T, Fowler N, Anne S: Evaluation of unilateral sensorineural hearing loss in the pediatric patient. Int J Pediatr Otorhinolaryngol 77:955-958, 2013

11. Hagiwara M, Shaikh JA, Fang Y, Fatterpekar G, Roehm PC: Prevalence of radiographic semicircular canal dehiscence in very young children: an evaluation using high-resolution computed tomography of the temporal bones. Pediatr Radiol 42:1456-1464, 2012

12. Henderson RC, Lark RK, Gurka MJ, Worley G, Fung EB, Conaway M, et al: Bone density and metabolism in children and adolescents with moderate to severe cerebral palsy. Pediatrics 110:e5, 2002

13. Hildebrand MS, Tack D, Deluca A, Hur IA, Van Rybroek JM, McMordie SJ, et al: Mutation in the COCH gene is associated with superior semicircular canal dehiscence. Am J Med Genet A 149A:280-285, 2009

14. Jackson NM, Allen LM, Morell B, Carpenter CC, Givens VB, Kakade A, et al: The relationship of age and radiographic incidence of superior semicircular canal dehiscence in pediatric patients. Otol Neurotol 36:99-105, 2015

15. Kanaan AA, Raad RA, Hourani RG, Zaytoun GM: Bilateral superior semicircular canal dehiscence in a child with sensorineural hearing loss and without vestibular symptoms. Int J Pediatr Otorhinolaryngol 75:877-879, 2011

16. Kao CH, Chen CC, Wang SJ, Yeh SH: Bone mineral density in children with Down's syndrome detected by dual photon absorptiometry. Nucl Med Commun 13:773-775, 1992

17. Karimnejad K, Czerny MS, Lookabaugh S, Lee DJ, Mikulec AA: Gender and laterality in semicircular canal dehiscence syndrome. J Laryngol Otol 130:712-716, 2016

18. Lee GS, Zhou G, Poe D, Kenna M, Amin M, Ohlms L, et al: Clinical experience in diagnosis and management of superior semicircular canal dehiscence in children. Laryngoscope 121:2256-2261, 2011

19. Locatelli V, Bianchi VE: Effect of GH/IGF-1 on bone metabolism and osteoporsosis. Int J Endocrinol 2014:235060, 2014

20. Meiklejohn DA, Corrales CE, Boldt BM, Sharon JD, Yeom KW, Carey JP, et al: Pediatric semicircular canal dehiscence: radiographic and histologic prevalence, with clinical correlation. Otol Neurotol 36:1383-1389, 2015

21. Minor LB, Solomon D, Zinreich JS, Zee DS: Sound- and/or pressure-induced vertigo due to bone dehiscence of the superior semicircular canal. Arch Otolaryngol Head Neck Surg 124:249-258, 1998

22. Nadgir RN, Ozonoff A, Devaiah AK, Halderman AA, Sakai O: Superior semicircular canal dehiscence: congenital or acquired condition? AJNR Am J Neuroradiol 32:947-949, 2011

23. Noonan KY, Russo J, Shen J, Rehm H, Halbach S, Hopp E, et al: $\mathrm{CDH} 23$ related hearing loss: a new genetic risk factor for semicircular canal dehiscence? Otol Neurotol 37:1583-1588, 2016

24. Pfammatter A, Darrouzet V, Gärtner M, Somers T, Van Dinther J, Trabalzini F, et al: A superior semicircular canal dehiscence syndrome multicenter study: is there an association between size and symptoms? Otol Neurotol 31:447-454, 2010

25. Pujol J, López-Sala A, Deus J, Cardoner N, Sebastián-Gallés $\mathrm{N}$, Conesa $\mathrm{G}$, et al: The lateral asymmetry of the human brain studied by volumetric magnetic resonance imaging. Neuroimage 17:670-679, 2002 
26. Rogol AD: Sex steroids, growth hormone, leptin and the pubertal growth spurt. Endocr Dev 17:77-85, 2010

27. Rogol AD, Roemmich JN, Clark PA: Growth at puberty. J Adolesc Health 31 (6 Suppl):192-200, 2002

28. Roknic N, Huber A, Hegemann SC, Häusler R, Gürtler N: Mutation analysis of Netrin 1 and HMX 3 genes in patients with superior semicircular canal dehiscence syndrome. Acta Otolaryngol 132:1061-1065, 2012

29. Saxby AJ, Gowdy C, Fandiño M, Chadha NK, Kozak FK, Sargent MA, et al: Radiological prevalence of superior and posterior semicircular canal dehiscence in children. Int J Pediatr Otorhinolaryngol 79:411-418, 2015

30. Schutt CA, Neubauer P, Samy RN, Pensak ML, Kuhn JJ, Herschovitch M, et al: The correlation between obesity, obstructive sleep apnea, and superior semicircular canal dehiscence: a new explanation for an increasingly common problem. Otol Neurotol 36:551-554, 2015

31. Sugihara EM, Babu SC, Kitsko DJ, Haupert MS, Thottam PJ: Incidence of pediatric superior semicircular canal dehiscence and inner ear anomalies: a large multicenter review. Otol Neurotol 37:1370-1375, 2016

32. Thabet EM: Ocular vestibular evoked myogenic potentials n10 response in autism spectrum disorders children with auditory hypersensitivity: an indicator of semicircular canal dehiscence. Eur Arch Otorhinolaryngol 271:1283-1288, 2014

33. Tsunoda A, Terasaki O: Dehiscence of the bony roof of the superior semicircular canal in the middle cranial fossa. J Laryngol Otol 116:514-518, 2002

34. Wenzel A, Stuck BA, Servais JJ, Hörmann K, Hülse M, Hülse R: Superior canal dehiscence syndrome in children-a case report. Int J Pediatr Otorhinolaryngol 79:1573-1578, 2015
35. Yunker WK, Walen SG, Lange EJ: Vestibular pathology presenting as behavioral problems in a child with Down syndrome: a case report. J Dev Behav Pediatr 30:66-68, 2009

36. Zhou G, Ohlms L, Liberman J, Amin M: Superior semicircular canal dehiscence in a young child: implication of developmental defect. Int J Pediatr Otorhinolaryngol 71:1925-1928, 2007

\section{Disclosures}

Dr. Yang reports having a consultant relationship with BrainLab and Baxter.

\section{Author Contributions}

Conception and design: Yang, Lagman, Fong, Wang, Gopen. Acquisition of data: Lagman, Ong, Chung, Fong, Gopen. Analysis and interpretation of data: Lagman, Ong, Chung, Elhajjmoussa, Fong, Wang. Drafting the article: all authors. Critically revising the article: all authors. Reviewed submitted version of manuscript: all authors. Approved the final version of the manuscript on behalf of all authors: Yang. Statistical analysis: Lagman, Ong. Study supervision: Yang, Lagman, Wang, Gopen. Provided original illustration (Fig. 2): Elhajjmoussa.

\section{Correspondence}

Isaac Yang, Department of Neurosurgery, David Geffen School of Medicine, University of California, Los Angeles, 300 Stein Plaza, Ste. 562, Los Angeles, CA 90095-6901. email: iyang@mednet. ucla.edu. 